\title{
UCRL-CONF-215030
}

\section{OPTIMIZATION OF EXPERIMENTAL DESIGNS BY INCORPORATING NIF FACILITY IMPACTS}

D. C. Eder, P. K. Whitman, A. E. Koniges, R. W. Anderson, P. Wang, B. T. Gunney, T. G. Parham, J. G. Koerner, S. N. Dixit, T. I . Suratwala, B. E. Blue, J. F. Hansen, M. T. Tobin, H. F. Robey, M. L. Spaeth, B. J. MacGowan

September 6, 2005

2005 Fourth International Conference on Interial Fusion Science and Applications Biarritz, France

September 4, 2005 through September 9, 2005 
This document was prepared as an account of work sponsored by an agency of the United States Government. Neither the United States Government nor the University of California nor any of their employees, makes any warranty, express or implied, or assumes any legal liability or responsibility for the accuracy, completeness, or usefulness of any information, apparatus, product, or process disclosed, or represents that its use would not infringe privately owned rights. Reference herein to any specific commercial product, process, or service by trade name, trademark, manufacturer, or otherwise, does not necessarily constitute or imply its endorsement, recommendation, or favoring by the United States Government or the University of California. The views and opinions of authors expressed herein do not necessarily state or reflect those of the United States Government or the University of California, and shall not be used for advertising or product endorsement purposes. 


\title{
XXXXXX \\ OPTIMIZATION OF EXPERIMENTAL DESIGNS BY INCORPORATING NIF FACILITY IMPACTS
}

\author{
D. C. Eder, P. K. Whitman, A. E. Koniges, R. W. Anderson, P. Wang, B. T. Gunney, T. G. \\ Parham, J. G. Koerner, S. N. Dixit, T. I. Suratwala, B. E. Blue, J. F. Hansen, M. T. Tobin, \\ H. F. Robey, M. L. Spaeth, and B. J. MacGowan
}

\author{
LLNL, Livermore, CA, USA \\ deder@1lnl.gov
}

\begin{abstract}
For experimental campaigns on the National Ignition Facility (NIF) to be successful, they must obtain useful data without causing unacceptable impact on the facility. Of particular concern is excessive damage to optics and diagnostic components. There are 192 fused silica main debris shields (MDS) exposed to the potentially hostile target chamber environment on each shot. Damage in these optics results either from the interaction of laser light with contamination and pre-existing imperfections on the optic surface or from the impact of shrapnel fragments. Mitigation of this second damage source is possible by identifying shrapnel sources and shielding optics from them. It was recently demonstrated that the addition of 1.1-mm thick borosilicate disposable debris shields $(D D S)$ block the majority of debris and shrapnel fragments from reaching the relatively expensive $M D S^{\prime}$ s. However, DDS's cannot stop large, faster moving fragments. We have experimentally demonstrated one shrapnel mitigation technique showing that it is possible to direct fast moving fragments by changing the source orientation, in this case a Ta pinhole array. Another mitigation method is to change the source material to one that produces smaller fragments. Simulations and validating experiments are necessary to determine which fragments can penetrate or break 1-3 mm thick DDS's. Three-dimensional modeling of complex target-diagnostic configurations is necessary to predict the size, velocity, and spatial distribution of shrapnel fragments. The tools we are developing will be used to set the allowed level of debris and shrapnel generation for all NIF experimental campaigns.
\end{abstract}

\section{INTRODUCTION}

Experimental configurations for the National Ignition Facility (NIF) and Laser MegaJoule (LMJ) must be optimized to reduce any detrimental impact on the facility. Of particular concern is damage to optics and diagnostics by shrapnel fragments coming from target/diagnostics components. In addition, performance of optics can be degraded by debris from components that are generally completely vaporized, e.g., hohlraums, or from x-ray ablation of components with large surface areas. In general, the spatial distribution of shrapnel and debris is not isotropic and detailed $2 \& 3 \mathrm{D}$ simulations running out to times much longer the laser pulse are required to predict the loading on optics and diagnostics [1]. Progress 
in modeling debris and shrapnel is presented in a companion paper. [2]

In section II, we discuss the use of relatively inexpensive borosilicate glass as disposable debris shields (DDS's) to protect the more expensive fused silica main debris shields (MDS's). We show results on the first use of these DDS's on a series of NIF shots using four beams. In section III, we discuss how damage to a NIF detector was mitigated by making a change in a diagnostic component, tilt of an $\mathrm{x}$ ray pinhole, to direct shrapnel away from the detector. In section IV, we discuss the potential problem of narrow sprays of molten shrapnel on DDS's. We conclude in section V.

\section{DISPOSABLE DEBRIS SHIELDS}

We shield the most expensive optical components in the final optics assembly, such as the wedge focus lens, from the hostile target chamber environment, using a combination of DDS's and MDS's. This is in contrast to the majority of other laser facilities that use a single set of debris shields. The large-scale production of borosilicate glass for flat panel monitors, allows for their use as relatively inexpensive DDS's. However, this glass has sufficient nonlinear absorption of $3 \omega$ light to limit the thickness to 1-3 mm. This thickness is not sufficient to stop the largest and fastest fragments so an additional 1-cm thick fused silica MDS is placed behind the DDS. In addition, to providing additional protection from penetrations, the use of two debris shields helps with the problem of damage growth. By limiting the number of damage sites on the MDS's, they can remain in the chamber for many more shots than an unprotected MDS. The shot limit for an unprotected MDS is primarily set by the total scattering area of a very large number of relatively small damage sites. These damage sites are caused by laser damage, which is enhanced by debris on the surface, and shrapnel impact. In contrast, the shot limit for a protected MDS is primarily limited by growth of a relatively few damage sites making sure their size does not exceed the thickness of the optic. The shot limit for DDS's is determined by shrapnel penetration and to a less extent by debris induced transmission loss.

The use of DDS's in a target chamber was tested for the first time during a series of NIF shots in September and October of 2004. We placed DDS's on three of the four beam lines. On one of these beam lines, we changed the DDS a number of times during the series of 21 shots. In Fig. 1, we show the MDS that was unprotected by DDS's. The beam footprint is clearly seen, where debris is not removed by beam cleaning around the edge of the optic. A very large number of damage sites are seen in the optic associated with a combination of debris and modulations in the beam associated with upstream optics. Modeling predicted that any shrapnel generated during these shots would be directed away from the optics[2] and no shrapnel induced damage sites were observed on the unprotected MDS or any of the DDS's. One of the protected MDS's is shown in Fig.2. Essentially no debris reached this MDS so the beam footprint is visible and the number of laser induced damage sites is substantially reduced.

The transmission for all DDS's placed in the chamber was measured at the completion of the experiments and compared to DDS that were not used. The loss of transmission for the two DDS's that were in for all 21 shots was measured to be $\sim 2 \%$ less than the DDS not placed in the chamber. The loss in transmission for the DDS's that were in for fewer shots was measured to scale roughly with the number of shots they were in the chamber.

\section{DIRECTING SHRAPNEL}

One of the early hydrodynamic experiments on NIF showed the need to direct shrapnel away from sensitive components. During early operation the use of Be x-ray shields was 
limited making some detectors more sensitive to shrapnel impact. Shrapnel fragments penetrated a Ti x-ray shield and damaged the camera located behind the detector. The source of the shrapnel was determined to be a $50-\mu \mathrm{m}$ thick Ta pinhole foil. The side of the foil facing the backlighting foil is heated by $\mathrm{x}$ rays that drive a shock through the foil causing the backside of the foil to spall and fragment. Given our experience modeling and measuring shrapnel from laser shocked Ta foils, we decided that tilting the pinhole foil would direct the shrapnel away from the detector[3].

To confirm this predication, we conducted a set of experiments on the Omega laser[4]. We summarize the results here. In the first configuration, we placed two Ta foils symmetrically on either side of a Zn backlighter, which heated and drove shocks into foils. The shrapnel from the two foil was captured by a glass plate and by aerogel foam. In addition, an optical camera recorded the shrapnel spray leaving the foils. The sprays were narrow and normal to the rear surfaces. To demonstrate redirection, one of the Ta foils was tilted as shown in Fig. 3 and the resulting optical image is shown in Fig. 4. The tilted Ta pinhole was used successfully on subsequent NIF hydrodynamic experiments.

\section{DDS BREAKAGE}

In the first configuration of the tilt experiment at Omega, the 1-mm thick borosilicate glass capture plate broke. This was a concern since this is the same material used for DDS's. The majority of the fragments were collected and the reconfigured plate is shown in Fig. 5. We examined the glass fragments and concluded that the majority of the shrapnel striking the plate was molten Ta. This is contrast to our earlier laser shocked Ta experiments, where the majority of the fragments were solid. In that case, we used the sizes of damage sites on the borosilicate glass as a measure of the size/velocity of the fragments. In the case of molten fragments, it appears that the energy of the shrapnel is coupled into the entire plate causing breakage rather than isolated damage sites. A risk assessment of potential breakage of DDS's by a narrow spray of molten fragments indicates that there could be a problem and mitigation is required such as broadening the spray or directing it away from optics.

Subsequent experiments using a plastic overcoat on the Ta foil produced a much broader spray.

\section{CONCUSSIONS}

The use of DDS's was tested for the first time with very positive results. The laser fluence for this series of shots corresponds to $\sim 1 \mathrm{MJ}$ operation if all 192 beams were in operation. For operation in this energy range, these results show that DDS operation with up to $\sim 20$ shots/DDS appears possible. However, with all 192 beams in operation we expected penetration of DDS's by shrapnel fragments to reduce the number of shots for some number of the DDS's.

We have shown that for some configurations shrapnel can be directed away from sensitive components by tilting the shrapnel source. However, these same experiments showed the ability of narrow sprays of molten shrapnel to break thin borosilicate glass. Initial NIF DDS's will use the thicker $3 \mathrm{~mm}$ borosilicate glass. All targets will be evaluated for shrapnel and debris with particular attention to the state of the material and the spatial distribution.

\section{ACKNOWLEDGMENTS}

This work was performed under the auspices of the U.S. Department of Energy by the University of California, Lawrence Livermore National Laboratory Under Contract No. W7405-Eng-48. 


\section{REFERENCES}

[1] D. C. Eder, A. K. Koniges, O. S. Jones, M. M. Marinak, M. T. Tobin, and B. J. MacGowan, Nuclear Fusion 44, 709 (2004).

[2] A. E. Koniges, R. W. Anderson, P. Wang, B. T. N. Gunney, R. Becker, D. C. Eder, B. J. MacGowan , these proceedings.

[3] D. C. Eder, et al., 2003 IFSA Proceedings, p. 572 (2004) and M. T. Tobin, et al., 2003 IFSA

Proceedings, p. 588 (2004).

[4] B. E. Blue, J. F. Hansen, M. T. Tobin, D. C> Eder, and H. F. Robey, Review of Scientific Instruments 75, 4775 (2004).

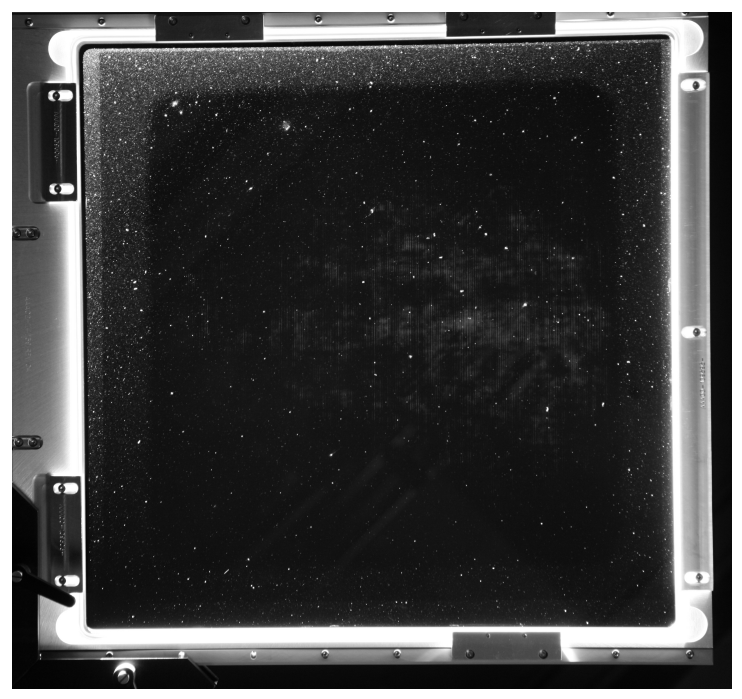

Figure 1. Unprotected NIF MDS.

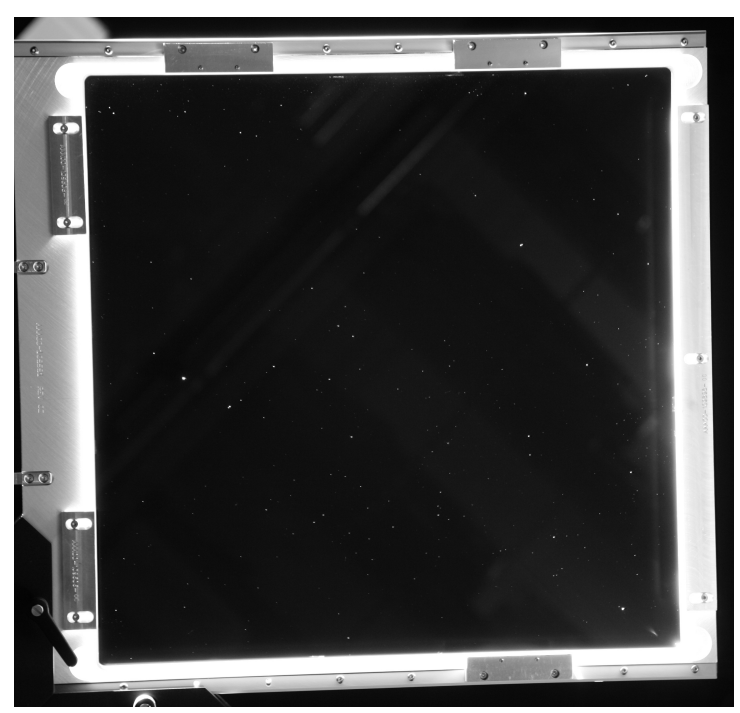

Figure 2. Protected NIF MDS.

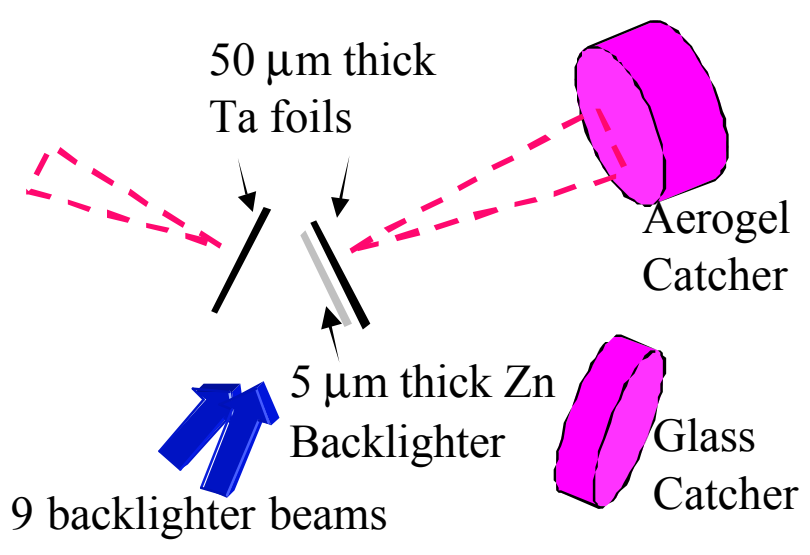

Figure 3. Second Omega configuration.

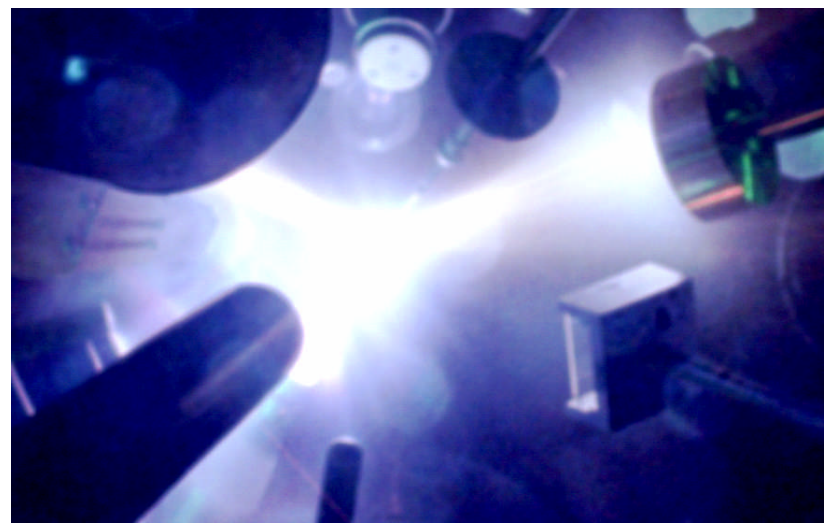

Figure 4. Omega experiment with tilted foil.

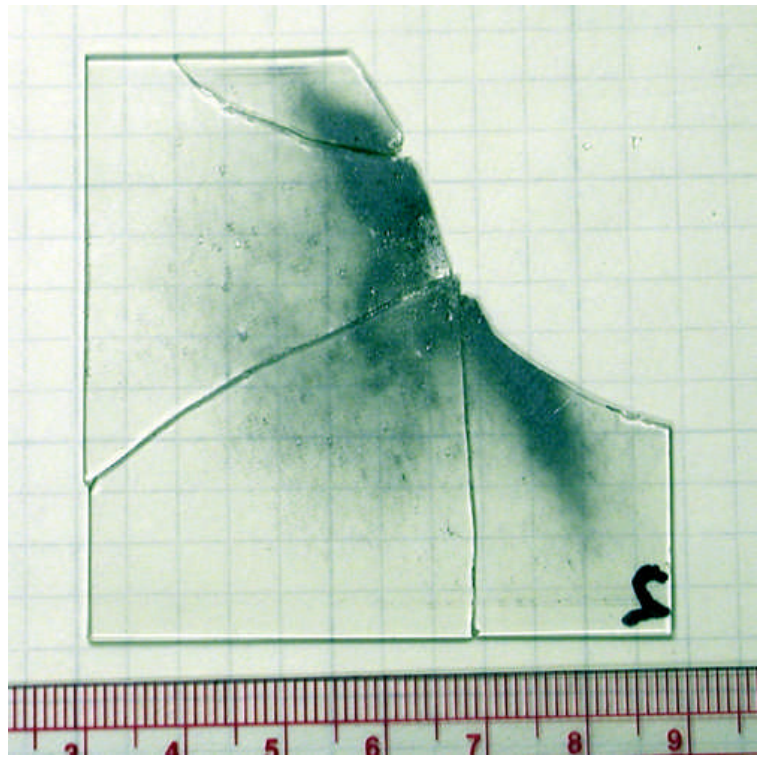

Figure 5. Reconfigured DDS sample plate. 
